\title{
A study on drug therapy issues in the department of medicine of a tertiary care teaching hospital-prospective observational study
}

\author{
Revathi J. ${ }^{1 *}$, Venkatesh V. P. ${ }^{1}$, Aswin C. ${ }^{1}$, Guru Prasad Mohanta ${ }^{1}$, Senthilvelan M. ${ }^{2}$
}

\author{
${ }^{1}$ Department of Pharmacy, Annamalai University, Chidambaram, Tamil Nadu, India \\ ${ }^{2}$ Department of Medicine, RMMCH, Annamalai University, Tamil Nadu, India
}

Received: 08 October 2021

Revised: 31 October 2021

Accepted: 01 November 2021

*Correspondence:

Dr. Revathi J.,

Email: reva.jana1031@gmail.com

Copyright: (C) the author(s), publisher and licensee Medip Academy. This is an open-access article distributed under the terms of the Creative Commons Attribution Non-Commercial License, which permits unrestricted non-commercial use, distribution, and reproduction in any medium, provided the original work is properly cited.

\begin{abstract}
Background: A drug therapy problem (DTP) is any undesirable event experienced by a patient that involves or is suspected to involve, drug therapy, and that interferes with achieving the desired goals of therapy. The improper use of drugs can lead to patient morbidity and even mortality. DTP s are the clinical territory of the pharmaceutical care practitioner and the resolution of identifying the DTPs help patients to achieve their goals of therapy. Identifying DTPs enables risk quantification and determination of the potential impact of prevention strategies. DTPs are associated with prolonged length of stay and increased economic burden and results in increased risk of death.

Methods: A hospital based, prospective observational study was conducted at department of medicine in Rajah Muthiah medical college and hospital, 80 patients were enrolled in this study based on the inclusion-exclusion criteria. The DTPs were identified using the Cipolle's method of classification of DTP.

Results: The study has shown that 80 of the patients involved in the study had a total of 136 DTPs. An average of 1.7 DTPs were recorded per patient during the study. The most common DTP identified was unnecessary drug therapy accounting to $47 \%$. The absence of valid medical indication was $(30 \%)$ and $(16 \%)$ were due to the duplication of therapy. The second most common DTP was unsafe drug for patients, accounting to $45 \%$ were due to patient noncompliance and drug interaction which was minor. Need for additional drug therapy was the third most identified accounting $13 \%$ were due to medical indication indicate the need of drug therapy.

Conclusions: The foremost commonly observed DTP is unnecessary therapy and patient non-compliance to the drugs. The study suggests that DTPs are significantly occurring in hospital can cause the patient for comorbidity, prolonged hospitalization. The study suggests that clinical pharmacist and general practitioners can work together to spot and resolve the DTPs.
\end{abstract}

Keywords: Drug therapy issue, Pharmaceutical care process, Patient non-compliance, Drug interactions

\section{INTRODUCTION}

A rational, safe, and cost-effective drug treatment depends on competent diagnosing, prescribing, effective monitoring and evaluation of drug therapy, patient understanding and compliance in reference to the prescribed medication. Clinical pharmacists may contribute significantly to form sure safe and effective medication use. Pharmacists may additionally play a major role in improving medication adherence behaviour in patients through patient education. They also play a significant role in reducing the incidence of preventable adverse drug reactions thereby improving cost effectiveness. Pharmaceutical care is that the responsible provision of drug therapy for the aim of achieving definite outcomes that improves patient's quality of life. The exercising of pharmaceutical care makes unique the pharmacist's responsibility to the patient for the prevention of medicine-related illness. During this practice the pharmacists evaluate the patient's therapy 
related needs, then determines one or more DTPs exists, and, if so, works with the patient and other health care professionals to style, implement and monitor a care plan.

\section{Pharmaceutical care process}

Pharmaceutical care is required to all or any patients receiving medications. A pharmaceutical care process is critical to forestall patients from DTPs. An honest communication is critical between the patient and thus the health care professional. To assess the patient, the pharmacist should consider all he patient and medicine factors that leads DTPs. The assessment process involves speaking to the patient, physicians and reviewing the medication chart, while the target is on DTPs, the procedure allows the identification of disease related problems because the therapeutic approach is verified and validated. The identified DTP should be delivered to the notice of patients and other professionals for the event of effective and safe care plan. Prioritize the DTP: The identified DTP should be prioritized in line with the patient's disease condition and so the severity of the matter. Develop a monitoring strategy: The progress towards the achievement of therapeutic goals should be monitored at specific intervals or periodically to further review. Document the care plan: The record of DTPs and also the therapeutic goals, along with the proposed actions, form a documented pharmaceutical care plan. The pharmaceutical care plan is often implemented with the consent of the patient and co-operation with other health care professionals. The outcomes of the care plan are evaluated in relevance to the therapeutic goal so as to see whether the DTP has solved and also the goal is attained. If the goal isn't achieved, alternative plan could even be necessary.

\section{DTPs}

A DTP is defined as "an undesirable event, a patient experience that involves, or is suspected to involve drug therapy, which actually or potentially, interferes with a desired patient outcome". ${ }^{1}$ The DTPs can occur at any stages of the treatment from prescribing to administration. DTP possess a decent challenge to the clinicians affecting the required therapeutic outcome and increased morbidity and mortality.

\section{Categories of DTP as per Cipolle}

Cipolle et al proposed the subsequent categories of DTPs: 6

Appropriate indication for the medication: This includes the patients who require additional drug therapy or receiving unnecessary drug therapy.

Needing drug therapy but not receiving it: A DTP occurs when there's a medical condition needing drug therapy or preventive therapy or combination treatment for better efficacy.
Receiving unnecessary drug therapy: A DTP that happens when there's no valid medical indication for the drug prescribed or multiple drug products were prescribed where one drug is efficient.

Receiving wrong medicine: The prescribed drug isn't effective for the indication present or the condition is refractory to the drug product being employed or the dosage form is inappropriate.

Dosage too low: It's a DTP that happens when the dose is just too low for the specified therapeutic action or too infrequent dosage interval or too short drug therapy duration.

Too much of the proper drug: The dose is just too high or the dosing frequency is simply too short or the duration of drug therapy is just too long or the dose was administered too rapidly.

Adverse drug reaction: the drug product causes an undesirable reaction that's not dose related or a safer drug is required for patient risk factors, or a drug interaction causes an undesirable reaction that's not dose related. A DTP that happens when the patient doesn't understand the instructions or the patient prefers to not take or forgets to intake the medication or the value of the drug isn't affordable or the drug product not available. Thus, the role of clinical pharmacist is to spot and endorse utilisation of safe and effective medications to resolve the DTPs, by analysing the medication regimen to be cost effective, safe and appropriate. Identification of DTPs and awareness on drugs which have risk of DTPs are essential components of treatment which can lessen DTPs, morbidity, mortality and improve personal satisfaction of patients. The main objective of the study is to identify the DTPs from the patient's medication history.

\section{METHODS}

\section{Study design}

A hospital based prospective observational study was undertaken from November 2019 to April 2020 in Rajah Muthiah medical college and hospital, a 1400 bedded multi-specialty, tertiary teaching hospital located in South India. The study protocol was endorsed by the human research ethics committee of the institute prior to commencement of the study (Approval letter NO IHEC/565/2019 dated 20.12.19). The sample size was calculated using the software tool-OPENEPI supported by centers for disease control and prevention.

\section{Study participants}

Patients admitted in the medicine department of the hospital during the study period were included in the study. The recruitment of the subject was carried out with the help of physician who has knowledge of patient's medical history. 


\section{Study procedure}

A well-designed form data collection form was prepared. The study materials included the case sheets of the patient, data collection form and the ADR reporting form.

The data collection form used in this study consists of patient's demographic characters including age, sex, diagnosis, comorbid medical conditions, administered drug's name, indication, dose, schedule, duration of the therapy. the type of DTP identified.

Prior to the initiation of the study, the procedure was explained to the patients who volunteered and fulfilled the inclusion criteria and the informed consent was obtained,

The patients were routinely monitored for the medications given during their hospital stay. The medication charts were followed till the discharge of each patient.

All the medication data were checked for DTPs using the Medscape. Drugs.com and drug bank databases and various pharmacology textbooks along with the interview of patients for OTC medication history and evaluated, whenever an ADR was suspected it was recorded in the ADR reporting form.

\section{Statistical analysis}

The data was collected and entered in the Microsoft excel software 2007 and interpreted by descriptive statistics that was presented to analyze and express the reports as counts and percentages in the form of tables, charts and graphs.

\section{RESULTS}

\section{Socio-demographic characteristics of the study participants}

During the six-month study period, a total of 80 cases were collected. Among which 18 were females and 62 were males. Thirty participants were in age group ranging 50 years, 26 participants were in the age group ranging $50-60$ years and rest of the participants were above the age of 65 .

Table 1: Socio demographic characteristics of the patients.

\begin{tabular}{|lll|}
\hline Variables & & No. of patients \\
\hline \multirow{4}{*}{ Age (years) } & Less than 50 & 30 \\
\cline { 2 - 3 } & $50-60$ & 26 \\
\cline { 2 - 3 } Sex & More than 60 & 24 \\
\hline & Female & 18 \\
\cline { 2 - 3 } & Male & 62 \\
\hline
\end{tabular}

\section{Clinical diagnosis}

All of the study participants were diagnosed with at least one disease by the physicians. A total of 139 diseases were reported of which 40 were reported with one disease, 24 were diagnosed with two diseases, 13 were diagnosed with three disease and the remaining 3 patients were diagnosed with four diseases.

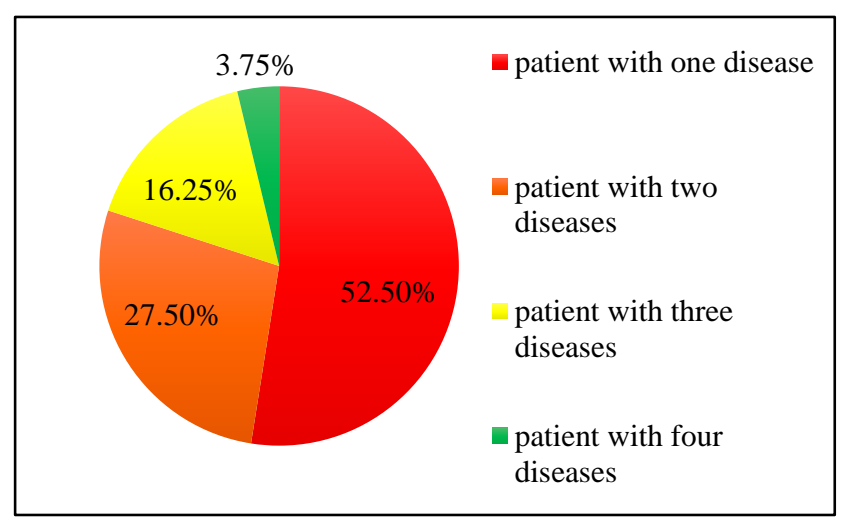

Figure 1: Clinical diagnosis in medicine ward.

The most commonly diagnosed diseases were cardiovascular disease, gastrointestinal disease, respiratory tract infections, central nervous system disorders, hematologic and endocrinologic disorders.

Table 2: Frequency of diseases in the medicine ward.

\begin{tabular}{|l|l|}
\hline Diagnosed diseases & No. of patients $(\%)$ \\
\hline Cardiologic disorders & $28(32.37)$ \\
\hline Endocrinologic disorders & $42(30.21)$ \\
\hline CNS & $20(14.38)$ \\
\hline RTI & $14(10.07)$ \\
\hline GI disorders & $8(5.75)$ \\
\hline Hepatic & $6(4.31)$ \\
\hline UTI & $3(2.15)$ \\
\hline Hematologic & $1(0.71)$ \\
\hline
\end{tabular}

\section{Prevalence of DTP}

A total of 136 DTPs were identified during the study period involving 61 out of 80 patients. Of the total patients with DTP; 20 had at least one DTP, 19 patients had two DTPs, 10 of the patients had three DTPs and the remaining 12 patients had at most four DTPs.

Table 3: Identified DTPs.

\begin{tabular}{|ll|}
\hline Type of DTP identified & $\mathbf{N}(\%)$ \\
\hline Unnecessary DTP & $47(34)$ \\
\hline Non-compliance & $45(33)$ \\
\hline Need for additional therapy & $13(9)$ \\
\hline Incorrect dose & $5(4)$ \\
\hline Drug interactions & $26(20)$ \\
\hline
\end{tabular}


The average hospital stay of the patients in the medicine ward was 5.2 days range $=2$ to 9 . A total of 433 medications were prescribed for the studied patient during the hospital stay. Average utilization was 7 medications per patient ranging 2 to 12 .

Table 4: Utilized medications in the medicine ward.

\begin{tabular}{|ll|}
\hline Medications & N \\
\hline Antibiotics & 61 \\
\hline Diuretics & 26 \\
\hline Others & 70 \\
\hline NSAID & 5 \\
\hline Anti-coagulant & 14 \\
\hline Antacid and anti-ulcerant & 42 \\
\hline Hypo-glycemic agents & 35 \\
\hline Anti-psychotics & 21 \\
\hline Anti-epileptics & 18 \\
\hline Anti-hypertensives & 48 \\
\hline Anti-hyper-lipidemia & 8 \\
\hline Supplements & 13 \\
\hline
\end{tabular}

The most common drug classes involved in the DTP were anti-ulcerant (26\%), antibiotic (22\%), anti-histamine $(22 \%)$, NSAID (3\%), anti-hypertensives (3\%) and others $(16 \%)$. Cefotaxime had the highest percentage of DTPs.

The most common DTP identified was unnecessary drug therapy accounting to $47 \%$. The absence of valid medical indication was $(30 \%)$ and $(16 \%)$ were due to the duplication of therapy.

The second most common DTP was unsafe drug for patients, accounting to $45 \%$ were due to patient noncompliance as well as the drug interaction which was minor.

Need for additional drug therapy was the third most identified accounting $13 \%$ were due to medical indication indicate the need of drug therapy. The non-compliance to medication was due to the inability of the patient to afford the medication and unaware about the drug indication and usage.

\section{DISCUSSION}

The study has shown that 80 of the patients involved in the study had a total of 136 DTPs. An average of 1.07 DTPs were recorded per patient during the study. This is comparable to the result of the study in Norway which reported $81 \%$ of the hospitalised patients had DTPs. ${ }^{18}$ During this study a mean of 1.07 DTPs were recorded per patient. This is also comparable to the result of the study at the medical wards of Gre-noble university hospital within which a mean of 1.71 DRPs were identified per patient. ${ }^{19}$ But in line with a retrospective study in Australia, 4.6 DTPs were identified per patient. ${ }^{20}$ This is high as compared to the results of our study and therefore the reason could also be due to lower number of diagnosed diseases per patient during the study period which may possibly result in decreased occurrence of DTPs within the medical ward. The most common DTP identified was unnecessary drug therapy accounting to $47 \%$. The absence of valid medical indication was $(30 \%)$ and $(16 \%)$ were due to the duplication of therapy. This is comparable to the result of a prospective observational study which was conducted in JUSH during which unnecessary dug therapy was the foremost common DTP identified $(24.2 \%)$ followed by needs additional drug therapy, 22.8\%; noncompliance, $19.5 \%$ and dosage too low, $12.1 \% .^{21}$ The second most common DTP was unsafe drug for patients, accounting to $45 \%$ were due to patient non-compliance and drug interaction which was minor. Noncompliance which was comparable to the result of the study in the medical ward of JUSH (19.55\%). ${ }^{21}$ Need for additional drug therapy was the third most identified accounting $13 \%$ were due to medical indication indicate the need of drug therapy. A number of studies have been reported that the inclusion of a clinical pharmacist in the patient health care at the inpatient hospital setting had shown safer and efficient drug usage through recognizing, solving and averting the DTPs. As a conclusion it is suggested to provide pharmaceutical care service at the hospital settings. ${ }^{3}$

\section{Limitations}

As the restraint, the study doesn't suggest the severity and results of the identified DTPs. The information regarding the medication history and over the counter medication use were obtained from the patients and their caretakers as the evidence were minimal. The identification of the adverse drug reactions was obtained from the conclusion of physicians thus the results may be a misjudged count of ADR. When a DTP was found the physicians were informed for ethical reasons and hence there was furthermore decrease in the DTPs.

\section{CONCLUSION}

The foremost commonly observed DTP is unnecessary therapy and patient non-compliance to the drugs. Drugs may be a useful gizmo within the prevention and treatment of symptoms and diseases, but if not used properly, they'll be harmful and causes sub-optimal effects which are termed as DTPs. Our study suggests that DTPs are significantly occurring in hospital can cause the patient for comorbidity, prolonged hospitalization. The study suggests that clinical pharmacist and general practitioners can work together to identify and resolve the DTPs.

\section{ACKNOWLEDGEMENTS}

Author would like to thanks to professor and head, department of pharmacy, Annamalai university, Rajah Muthiah medical college and hospital, Annamalai university. We would like to thank the patients who gave their consent and participated in the study. Finally, many 
thanks to all the people who helped us in the study and enabled this study to be possible.

Funding: No funding sources

Conflict of interest: None declared

Ethical approval: The study was approved by the Institutional Ethics Committee

\section{REFERENCES}

1. Weidenmayer K. Pharmacists in patient care: A practice perspective. In: Davey, S (ed.) Developing pharmacy practice. Netherlands: World Health Organisation and International Pharmaceutical Federation. 2006;23-33.

2. Adusumilli PK, Adepu R. Drug related problems: an over view of various classification systems. Asian $\mathrm{j}$ pharmaceutical clin res. 2014;7(4):7-8.

3. Belayneh YM, Amberbir M, Agalu A. A prospective observational study of drug therapy problems in medical ward of a referral hospital in northeast Ethiopia. BMC health service res. 2018;18(808):1-7.

4. Van mil JWF. Developing DRP classification. Developing a DRP classifications-a never ending story? Weblog. Available at: https://www.google.com/url?Sa=t\&source=web\&rct =j\&url=https://www.pcne.org/upload/ws2009/DRP\% 2520Vanmil\%2520Pres.pdf \&ved=2ahukewisuq23wo vqahu873mbhdjldnoqfjaaegqiahab\&usg=aovvaw0lof iuoedhjatoynsei5fk. Accessed 15 June 2020.

5. Greeshma M, Maheshwari E, Lency S, Tharanath S. Identification of drug related problems by clinical pharmacist in prescription with polypharmacy: a prospective interventional study. J young pharm. 2018;10(4):460-65.

6. Cipolle RJ, Strand LM, Morley PC. Pharmaceutical care practices the clinician's guide. $2^{\text {nd }}$ ed. New York: mcgraw-Hill. 2004.

7. Kjeldsen LJ, Høgh nielsen TR, Olesen C. Investigating the Relative Significance of DrugRelated Problem Categories. J Pharmacy, education practice. 2017;5(31):1-18.

8. Shastry S, Prudhivi R, Vidhya S, Lugun A, Mounika TS. Pattern of pharmacotherapy and assessment of drug related problems in ischemic heart disease patients. Int res j pharmacy. 2019;10(3):136-7.

9. Khan AU, Ali I, Zafar R, Khalil A. Identification of drug-related problems and pharmacist's interventions in asthmatic patients at a private tertiary care facility-Pakistan. Arch Practice. 2015;6(2):33-4.

Pharmacy

10. Garedow AW, Bobasa EM, Wolide AD, Dibaba FK, Fufa FG. Drug-Related Problems and Associated Factors among Patients Admitted with Chronic
Kidney Disease at Jimma University Medical Center, Jimma Zone, Jimma, Southwest Ethiopia: A Hospital-Based Prospective Observational Study. Hindawi Int Nephrol. 2019;2019(1504371):2-3.

11. Mohammed S, Poudel S, Laloo F, Madhur A, Robert R. Assessment of drug related problem in a tertiary care teaching hospital, India. Asian $\mathrm{j}$ pharmaceutical clin res. 2017;10(2):310-13.

12. Senthil Kumar N, Reji GK, Vijayarangan S, Ramya A. Prescription analysis and prevalence of potentially inappropriate medication use in older adults: an observational study. Int $\mathbf{J}$ pharmacy pharmaceutical sci. 2020;12(2):108-11.

13. Niriayoi YL, Kumela K, Kassa TD, Angamo MT. Drug therapy problems and contributing factors in the management of heart failure patients in Jimma University Specialized Hospital, Southwest Ethiopia. Plos ONE. 2018;10(1371):1-14.

14. Nascimento YA, Carvalho WS, Acurcio FA. Drugrelated problems observed in a pharmaceutical care service, Belo Horizonte, Brazil. Braz J Pharmaceutical Sci. 2009;45(2):321-8.

15. Tripathi KD. Essentials of medical pharmacology. $7^{\text {th }}$ ed. New Delhi: Jaypee brothers' medical publishers. 2013.

16. Sharma S, Sethi GR. Standard treatment guidelines $5^{\text {th }}$ ed. India: Wolters Kluwer. 2018.

17. Strand LM, Morley PC, Cipolle RJ, Ramsey R, Lamsam GD. Drug-related problems: Their structure and function. DICP. 1990;24(11):1093-7.

18. Blix HS. Drug-related problems in hospitalized patients: Unipub AS. University of Oslo Library. 2007;36-7.

19. Bedouch P, Allenet B, Grass A, Labarere J, Brudieu E, Bosson JL, Calop J. Drug-related problems in medical wards with a computerized physician order entry system. J clin pharm ther. 2009;34(2):187-95.

20. Stafford A, Tenni P, Peterson G, Jackson S, Hejlesen A, Villesen C, Rasmussen M. Drug-related problems identified in medication reviews by Australian pharmacists. Pharm World Sci. 2009;31:216-23.

21. Mekonnen AB, Yesuf EA, Odegard PS, Wega SS. Implementing ward based clinical pharmacy services in an Ethiopian University Hospital. Pharmacy practice. $2013 ; 11(1): 51$.

Cite this article as: Revathi J, Venkatesh VP, Aswin C, Mohanta GP, Senthilvelan M. A study on drug therapy issues in the department of medicine of a tertiary care teaching hospital-prospective observational study. Int J Basic Clin Pharmacol 2021;10:1405-9. 